Leimbach, Martin; Tschaar, Christoph; Zapf, David; Kurniawan, Mario; Schmidt, Udo; Bund, Andreas:

Relation between color and surface morphology of electrodeposited chromium for decorative applications

Original published in: Journal of the Electrochemical Society / Electrochemical Society. Pennington, NJ : Electrochemical Soc.. - 166 (2019), 6, p. D205D211.

Original published: $\quad$ 2019-04-04

ISSN: $\quad 1945-7111$

DOI: $\quad 10.1149 / 2.0871906 j e s$

[Visited: 2019-07-09]

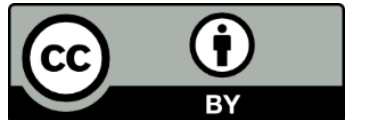

This work is licensed under a Creative Commons Attribution 4.0 International license. To view a copy of this license, visit http://creativecommons.org/licenses/BY/4.0 


\title{
Relation between Color and Surface Morphology of Electrodeposited Chromium for Decorative Applications
}

\author{
Martin Leimbach, ${ }^{1, *, z}$ Christoph Tschaar, ${ }^{1,2}$ David Zapf, ${ }^{2}$ Mario Kurniawan, ${ }^{1}$ \\ Udo Schmidt, ${ }^{1}$ and Andreas Bund $\mathbb{1}^{1, *}$
}

${ }^{1}$ Electrochemistry and Electroplating Group, Technische Universität Ilmenau, 98693 Ilmenau, Germany

${ }^{2}$ Hansgrohe SE, 77761 Schiltach, Germany

\begin{abstract}
Electrolytes for decorative chromium plating based on trivalent chromium salts are known since several decades. As the use of conventional, hexavalent chromium based plating baths is more and more restricted by governmental regulations, these electrolytes gain ground in electroplating industry. However, compared to hexavalent chromium electrolytes, trivalent chromium electrolytes cannot fully meet the requirements with regard to appearance of the electrodeposited chromium, and there is little knowledge about the influencing factors on the shade of color. In this paper, chromium plated from a solution of chromium(III) sulfate was characterized by colorimetry, SEM and AFM and compared to a sample plated from a chromic acid electrolyte in order to reveal correlations between visual appearance and surface morphology. A relation between an increase of grain size and a color shift from blueish to yellowish was observed. Unlike in hexavalent based systems, grain size, roughness and color depend on layer thickness as the grain growth mechanism appears to be different. A model based on the theory of light scattering at rough surfaces is provided that links roughness and reflection behavior of the chromium surface.

(C) The Author(s) 2019. Published by ECS. This is an open access article distributed under the terms of the Creative Commons Attribution 4.0 License (CC BY, http://creativecommons.org/licenses/by/4.0/), which permits unrestricted reuse of the work in any medium, provided the original work is properly cited. [DOI: 10.1149/2.0871906jes]

(cc) BY
\end{abstract}

Manuscript submitted February 11, 2019; revised manuscript received March 14, 2019. Published April 4, 2019.

Conventional electrolytes for the electrochemical deposition of chromium are based on compounds of hexavalent chromium like chromic acids. ${ }^{1}$ However, the usage of these substances in industrial processes is restricted in several countries because of their high toxicity and carcinogenicity. ${ }^{2}$ Electrolytes based on trivalent chromium compounds are promising alternatives considering process management and quality of the deposits. ${ }^{3,4}$ The deposition of functional chromium layers from solutions of chromium(III) salts is a frequently discussed topic in current research. ${ }^{5-7}$ For these applications, thick chromium layers up to a thickness of several hundred micrometers are essential to provide high hardness and wear resistance. On the other hand, only some tenth of micrometers are necessary for decorative applications of chromium. ${ }^{8}$ These layers have to protect the underlying metal substrate from corrosion and maintain a bright surface finish over long periods of time. For such applications, trivalent chromium based electrolyte formulations are already known since several decades. ${ }^{9}$

Although commercially available chromium(III) electrolytes can provide a bright surface finish, the color of the deposits differs from hexavalent based processes. ${ }^{10}$ While the surface of a chromium layer plated from chromium(VI)-based electrolyte has a blueish appearance, the color shifts to yellowish in case of chromium(III)-based solutions. Since the cause for that difference is not fully understood yet, an adjustment of the color is difficult, and the maintenance of a constant surface appearance during an industrial scale plating process becomes challenging. For some applications, dark colored chromium is achieved by addition of organic compounds due to the incorporation of carbon ${ }^{11}$ or sulfur $^{12}$ in the deposit. However, this is usually not the case for bright chromium electrolytes as the amount of foreign elements in the layer is comparably small. ${ }^{13}$

In this work, chromium layers were deposited from a chromium(III) sulfate based electrolyte and characterized by colorimetry, scanning electron microscopy (SEM) and atomic force microscopy (AFM). Spectral reflectance curves were measured and the $\mathrm{L}^{*} \mathrm{a}^{*} \mathrm{~b}^{*}$ color values were calculated therefrom. Changes in color were correlated to the surface morphology and compared to a sample plated from a chromic acid electrolyte. Finally, a model is proposed to support the relationship between structure and visual appearance of the chromium surface.

\section{Experimental}

Brass panels in the size $5 \mathrm{~cm}$ times $7.5 \mathrm{~cm}$ with a polished surface were used as substrates. These panels were degreased in a commercial alkaline electrolytic cleaner (HSO Uni 1, Herbert Schmidt GmbH Solingen) by applying a cathodic current of $2 \mathrm{~A} \mathrm{dm}^{-2}$ for $4 \mathrm{~min}$. Stainless steel served as anode material. Afterwards the samples were dipped in $10 \%$ sulfuric acid for activation and plated with $10 \mu \mathrm{m}$ of nickel in a commercial bright nickel electrolyte (Table I) using sulfurdepolarized nickel plates as anodes.

The final deposition of chromium was carried out in a sulfatebased chromium electrolyte (Table II). Besides the chromium(III) salt, buffer, supporting electrolyte and sodium dodecyl sulfate (SDS) as surfactant, the solution contains saccharine, facilitating the reduction to chromium metal. A more detailed discussion of the electrolyte properties can be found in our previous paper. ${ }^{13}$ Two liters of this electrolyte were used in a beaker with two parallel mixed metal oxide anodes (De Nora GreenChrome). During plating, the samples were moved in parallel to the anodes in an alternate motion at a velocity of $6 \mathrm{~cm} \mathrm{~s}^{-1}$ in order to facilitate mass transport and remove evolving hydrogen bubbles from the surface. The plating of chromium from a chromic acid electrolyte (Table III) for comparison was performed at the facilities of Hansgrohe SE.

For the measurement of the color, recommendations of the International Commission on Illumination (CIE) for colorimetry ${ }^{14}$ were followed. Samples were irradiated by visible light with a D65 standardized spectrum and the spectrum of the reflected light was detected under an angle of $8^{\circ}$ to normal. Both the specular and the diffuse reflected light were considered for analysis. A spectral photometer CM-700d from KONICA MINOLTA with a spot size of $6 \mathrm{~mm}$ was

Table I. Composition of the bright nickel electrolyte ELPELYT GS 6 (ENTHONE OMI).

\begin{tabular}{ll} 
Component & Concentration \\
\hline $\mathrm{Ni}^{2+}$ & $77 \mathrm{~g} \mathrm{l}^{-1}\left(1.3 \mathrm{~mol} \mathrm{l}^{-1}\right)$ \\
$\mathrm{Cl}^{-}$ & $18 \mathrm{~g} \mathrm{l}^{-1}$ \\
$\mathrm{H}_{3} \mathrm{BO}_{3}$ & $45 \mathrm{~g} \mathrm{l}^{-1}$ \\
Brightener GS 6 & $0.4 \mathrm{ml} \mathrm{l}^{-1}$ \\
Saccharine & $2.0 \mathrm{~g} \mathrm{l}^{-1}$ \\
$\mathrm{pH}$ & 4.2 \\
Temperature & $65^{\circ} \mathrm{C}$ \\
Current density & $5 \mathrm{~A} \mathrm{dm}^{-2}$
\end{tabular}




\begin{tabular}{ll} 
Table II. Composition of the chromium(III)-based electrolyte. \\
Component & Concentration \\
\hline $\mathrm{KCr}\left(\mathrm{SO}_{4}\right)_{2} \cdot 12 \mathrm{H}_{2} \mathrm{O}$ & $50 \mathrm{~g} \mathrm{l}^{-1}\left(0.1 \mathrm{~mol} \mathrm{l}^{-1}\right)$ \\
$\mathrm{H}_{3} \mathrm{BO}_{3}$ & $90 \mathrm{~g} \mathrm{l}^{-1}$ \\
$\mathrm{Na}_{2} \mathrm{SO}_{4}$ & $190 \mathrm{~g} \mathrm{l}^{-1}$ \\
Sodium dodecyl sulfate (SDS) & $0.2 \mathrm{~g} \mathrm{l}^{-1}$ \\
Saccharine sodium salt dihydrate & $2.0 \mathrm{~g} \mathrm{l}^{-1}\left(1.5 \mathrm{~g} \mathrm{l}^{-1}\right.$ saccharine) \\
$\mathrm{pH}$ & 3.2 \\
Temperature & $55^{\circ} \mathrm{C}$ \\
Current density & $5 \mathrm{~A} \mathrm{dm}^{-2}$
\end{tabular}

used. An average was calculated for each sample after measurements at 12 different positions. The thickness of the chromium layers was determined by X-ray fluorescence spectroscopy (XRF) using the device Fischerscope XDV at a voltage of $30 \mathrm{kV}$, spot size of $3 \mathrm{~mm}$ and measuring time of $30 \mathrm{~s}$ per position. Thickness values were collected for each sample from nine positions distributed uniformly over the surface and the average was calculated.

Scanning electron microscopy (SEM) and electron dispersive $\mathrm{X}$-ray spectroscopy (EDS) were made using the SEM Hitachi S4800 with secondary electron detector at an acceleration voltage of $5 \mathrm{kV}$ for imaging and $10 \mathrm{kV}$ for spectroscopy. The atomic force microscopy measurements were done using a Dimension Icon AFM device from Bruker Co. Billerica. All of the AFM images were taken with a ScanAsyst air cantilever probe and Peak Force Tapping mode with a setpoint value of $0.2 \mathrm{~V}$, scan size of $2 \mu \mathrm{m}$ and scan speed of $1 \mathrm{~Hz}$. The fast scan direction was set to horizontal and the scan was from the top to the bottom. The images were postprocessed using third-order polynomial flattening procedure by Nanoscope Analysis software from Bruker Co. Billerica to remove tilt and curvature. For better comparison of the results, the height scales were set at the same range.

\section{Results and Discussion}

Colorimetry.-Chromium layers with an average thickness of $20 \mathrm{~nm}, 140 \mathrm{~nm}$ and $380 \mathrm{~nm}$ were deposited and compared to a $140 \mathrm{~nm}$ chromium layer plated from a commercial electrolyte based on chromic acid. The spectral reflectance curves are shown in Figure 1 . The curve from the $20 \mathrm{~nm}$ sample has the maximum reflectance at a wavelength of about $470 \mathrm{~nm}$ and the minimum is observed at $620 \mathrm{~nm}$. Thus, the reflectance is higher in the blue-green range than in the yellow-red range, resulting in a blueish appearance of the surface. This curve shape is very similar to the shape of the spectrum of the sample plated from chromic acid electrolyte. However, the chromic acid sample shows higher overall reflectance, which means that the lightness is higher. As the thickness of the chromium layer from trivalent solution is increased, the maximum disappears and the reflectance in the blue range decreases. In case of the sample with $380 \mathrm{~nm}$ thickness, the reflectance is higher in the yellow-red range than in the blue-green, giving a yellowish appearance. Additionally, the overall reflectance is decreased.

From the measured reflectance curves, color values were calculated on the basis of the CIE colorimetric standards. ${ }^{15}$ The so-called

Table III. Composition of the chromic acid electrolyte.

\begin{tabular}{ll} 
Component & Concentration \\
\hline $\mathrm{CrO}_{3}$ & $395 \mathrm{~g} \mathrm{l}^{-1}\left(3.95 \mathrm{~mol} \mathrm{l}^{-1}\right)$ \\
$\mathrm{SO}_{4}{ }^{2-}$ & $2.5 \mathrm{~g} \mathrm{l}^{-1}$ \\
$\mathrm{~F}^{-}$ & $0.95 \mathrm{~g} \mathrm{l}^{-1}$ \\
$\mathrm{Cr}^{3+}$ & $2.4 \mathrm{~g} \mathrm{l}^{-1}$ \\
Temperature & $44.5^{\circ} \mathrm{C}$ \\
Current density & $10 \mathrm{~A} \mathrm{dm}^{-2}$
\end{tabular}

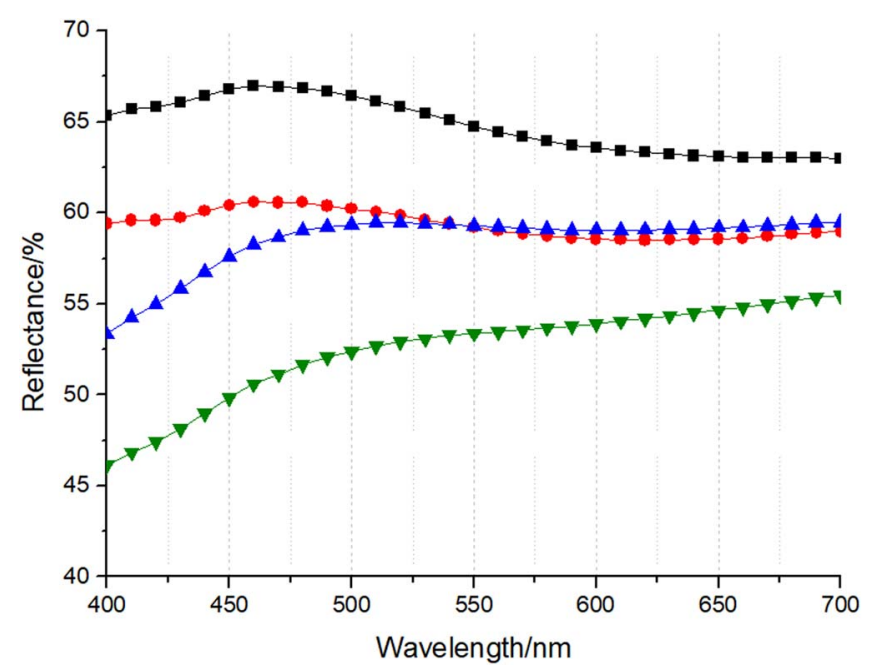

Figure 1. Spectral reflectance curves of chromium layers electroplated from chromium(III) with a thickness of $20 \mathrm{~nm}$ (red), $140 \mathrm{~nm}$ (blue) and $380 \mathrm{~nm}$ (green) and the sample plated from the chromic acid electrolyte (black).

tristimulus values $\mathrm{X}, \mathrm{Y}$ and $\mathrm{Z}$ can be obtained by Eqs. $1-4 .{ }^{16}$

$$
\begin{gathered}
X=K \cdot \int S(\lambda) \cdot R(\lambda) \cdot \bar{x}(\lambda) d \lambda \\
Y=K \cdot \int S(\lambda) \cdot R(\lambda) \cdot \bar{y}(\lambda) d \lambda \\
Z=K \cdot \int S(\lambda) \cdot R(\lambda) \cdot \bar{z}(\lambda) d \lambda \\
K=\frac{100}{\int S(\lambda) \cdot \bar{y}(\lambda) d \lambda}
\end{gathered}
$$

$S(\lambda)$ is the relative spectral power distribution of the illuminant, $\mathrm{R}(\lambda)$ the spectral reflectance of the specimen surface and $\bar{x}(\lambda)$, $\bar{y}(\lambda), \bar{z}(\lambda)$ the spectral sensitivity functions of the human eye. This quantification system is very close to human sense of color, but less convenient for comparisons. ${ }^{17}$ Therefore, the $\mathrm{L}^{*} \mathrm{a}^{*} \mathrm{~b}^{*}$ system (also referred as CIELAB) is used and $\mathrm{X}, \mathrm{Y}$ and $\mathrm{Z}$ are transformed to $\mathrm{L}^{*}, \mathrm{a}^{*}$ and $\mathrm{b}^{*}$ after Eqs. 5-7. ${ }^{18}$

$$
\begin{gathered}
L^{*}=116 \cdot \sqrt[3]{\frac{Y}{Y_{n}}}-16 \\
a^{*}=500 \cdot\left(\sqrt[3]{\frac{X}{X_{n}}}-\sqrt[3]{\frac{Y}{Y_{n}}}\right) \\
b^{*}=200 \cdot\left(\sqrt[3]{\frac{Y}{Y_{n}}}-\sqrt[3]{\frac{Z}{Z_{n}}}\right)
\end{gathered}
$$

For $\mathrm{X} / \mathrm{X}_{\mathrm{n}}>0.01, \mathrm{Y} / \mathrm{Y}_{\mathrm{n}}>0.01$ and $\mathrm{Z} / \mathrm{Z}_{\mathrm{n}}>0.01$ with $\mathrm{X}_{\mathrm{n}}, \mathrm{Y}_{\mathrm{n}}$ and $Z_{n}$ as standard values of a perfect reflecting diffuser. Figure 2 shows a plot of the results in the $\mathrm{L}^{*} \mathrm{a}^{*} \mathrm{~b}^{*}$ color space. In this system, $\mathrm{L}^{*}$ is the lightness parameter with values from 0 (black) to 100 (white). a* and $b^{*}$ indicate directions of the color hue, i. e. positive $a^{*}$ as red, negative $a^{*}$ as green, positive $b^{*}$ as yellow and negative $b^{*}$ as blue direction. The point $\mathrm{a}^{*}=\mathrm{b}^{*}=0$ is defined colorless and the chroma increases by increasing the absolute value. For the sake of clarity, $a^{*}$ and $b^{*}$ values are plotted in a 2D graph and the $\mathrm{L}^{*}$ value is represented separately.

The color values (Figure 2) show the same tendencies as the reflectance curves. The $b^{*}$ value of the $20 \mathrm{~nm}$ sample $(-0.7)$ and the sample from chromic acid electrolyte $(-1.5)$ are both the blue range 


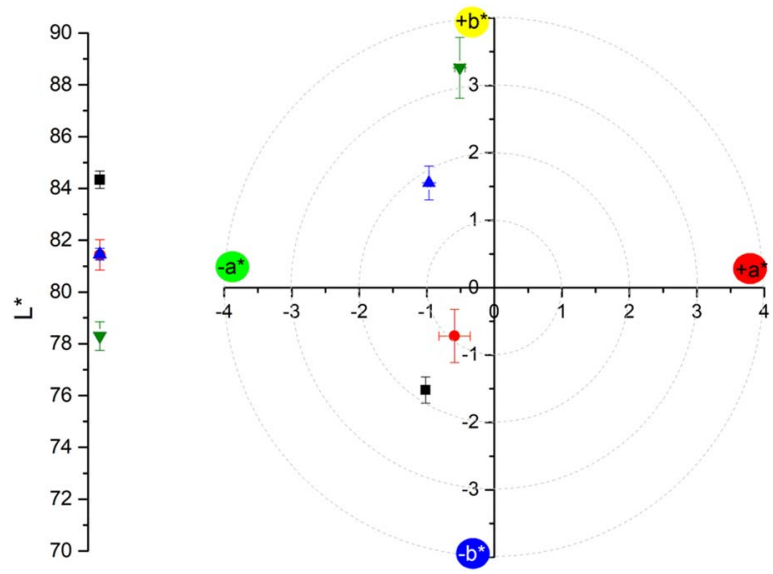

Figure 2. Representation of the color values calculated from the reflectance curves in Figure 1 in the $\mathrm{L}^{*} \mathrm{a}^{*} \mathrm{~b}^{*}$ color space. The markers indicate the color values of the layers electroplated from chromium(III) with a thickness of $20 \mathrm{~nm}$ (red), $140 \mathrm{~nm}$ (blue) and $380 \mathrm{~nm}$ (green) and the sample plated from the chromic acid electrolyte (black).

of the scale, whereas the blueish hue is even more pronounced for the latter one. By increasing the thickness, $b^{*}$ is shifting to positive, i. e. yellowish values $(+1.6$ for $140 \mathrm{~nm}$ layer thickness and +3.3 for $380 \mathrm{~nm}$ layer thickness). Large deviations in $\mathrm{b}^{*}$ compared to the other color values indicate that this parameter is very sensitive to variations in surface characteristics. The highest $\mathrm{L}^{*}$ value is reached by the sample from chromic acid electrolyte (84.3) and the lowest by the $380 \mathrm{~nm}$ thick chromium layer from chromium(III) (78.3), mirroring the intensity shift in the reflectance curves. The lightness of the other samples lies between these values and is about 81.4 for both. $\mathrm{a}^{*}$ has similar values for all the samples in the range of -0.5 and -1.0 . There is no clear trend for this parameter.

For a better interpretation of the parameter shift, $\mathrm{L}^{*}, \mathrm{a}^{*}$ and $\mathrm{b}^{*}$ are plotted versus thickness (Figure 3). A linear fit was done for each parameter. As already indicated by the results above, $\mathrm{L}^{*}$ is decreasing by increasing chromium thickness, while $\mathrm{a}^{*}$ shows no distinct trend and $b^{*}$ is increasing. The linear relationship is most prominent for $b^{*}$ since the scattering of the data points is comparably small. $\mathrm{b}^{*}=0$ is reached at a thickness of around $70 \mathrm{~nm}$. The chromium surface has a blueish color for a thickness below $70 \mathrm{~nm}$ and a yellowish hue for a thickness higher than $70 \mathrm{~nm}$.

Surface morphology studies.-The shift in color by increasing thickness can be correlated with a change of the surface morphology of the electroplated chromium. SEM images of the samples with an average thickness of 20, 140 and $380 \mathrm{~nm}$ were taken (Figure 4). The $20 \mathrm{~nm}$ layer exhibits a fine-grained structure with a grain size of around $40 \mathrm{~nm}$, which is close to the morphology of the sample plated from chromic acid (Figure 5) with a grain size between 20 and $40 \mathrm{~nm}$. Thus, the optical appearance is similar and the $b^{*}$ color values are both in the blue range. At higher thicknesses, the grain size of the samples from chromium(III) electrolyte is increasing to approximately $100 \mathrm{~nm}$ for the chromium sample with thickness of $140 \mathrm{~nm}$. Furthermore, the grain size is between 180 and $320 \mathrm{~nm}$ for the $380 \mathrm{~nm}$ sample.

This type of crystal growth is different to the growth mechanism in the hexavalent chromium based plating solutions. In the case of chromic acid electrolytes, the plated layer has a very fine, columnarlike grain structure ${ }^{19-21}$ as the nucleation rate is high and lateral growth
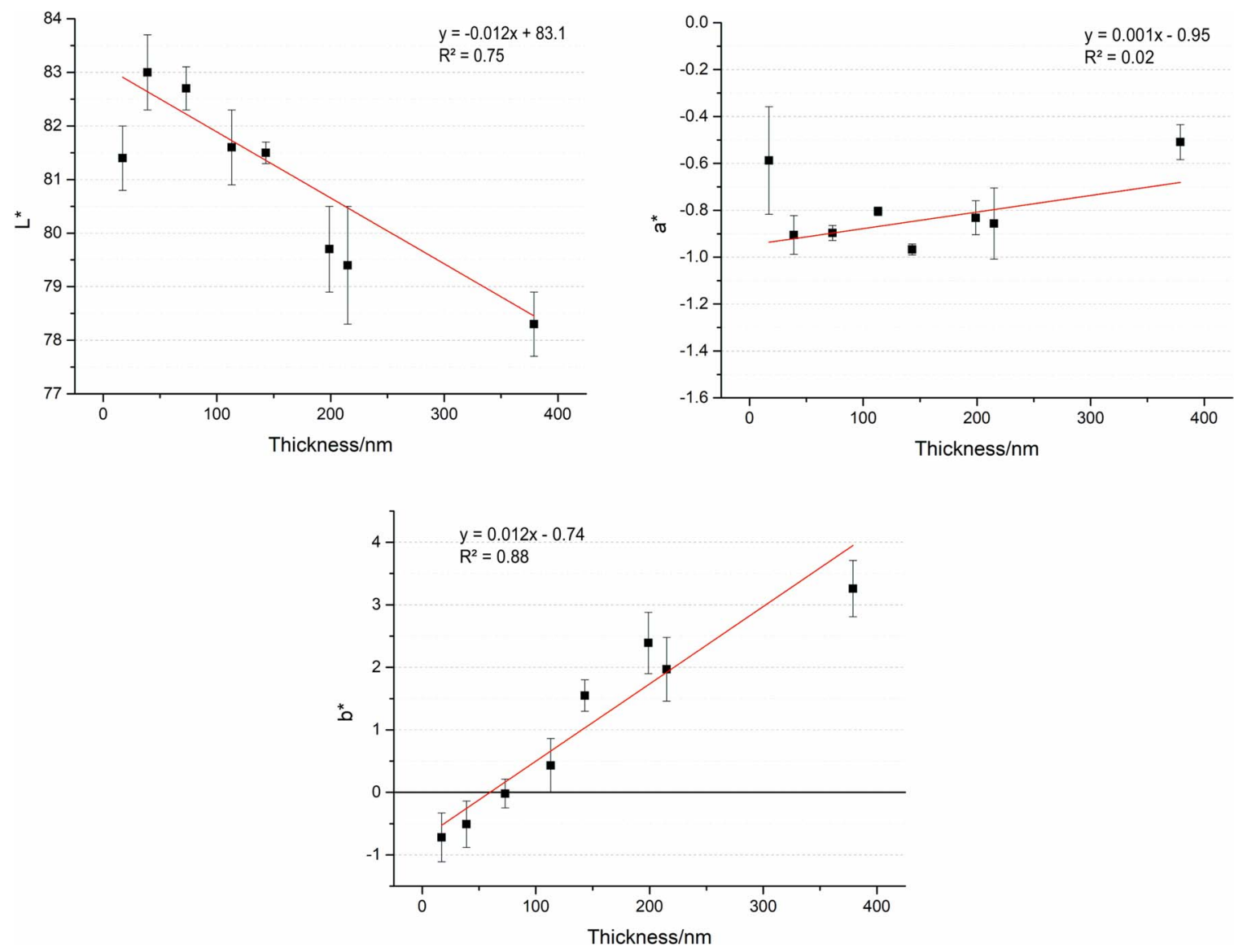

Figure 3. Plots of $\mathrm{L}^{*}, \mathrm{a}^{*}$ and $\mathrm{b}^{*}$ over thickness for chromium layers electroplated from the chromium(III)-based electrolyte (Table II). Trend lines and formula of the linear fit are indicated to expose linear dependencies between color values and thickness. 


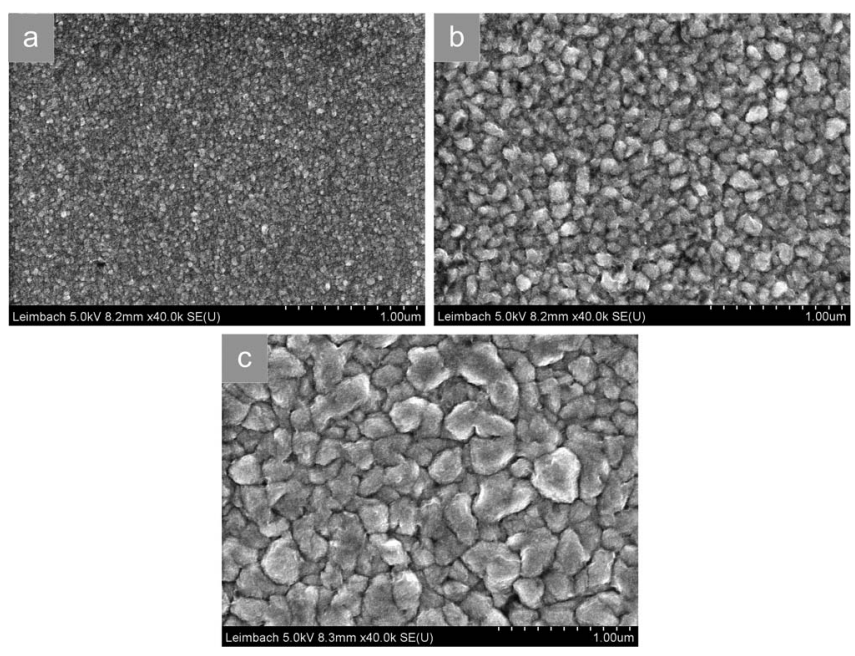

Figure 4. SEM images of the chromium layers electroplated from the chromium(III)-based electrolyte (Table II) with a layer thickness of a) $20 \mathrm{~nm}$, b) $140 \mathrm{~nm}$ and c) $380 \mathrm{~nm}$.

of chromium nuclei is suppressed. Therefore, the surface morphology is equally fine structured even at high layer thicknesses. For the chromium(III) based system, the number of nuclei is high as well at the beginning, but with proceeding deposition time, the nuclei growth exceeds the nuclei formation. This leads to a globular-like growth and a coarsening of the grain structure, as well as the morphology of the surface. Hence, the surface appearance is changing with increasing thickness.

The EDS measurements (Table IV) exhibit small contents of sulfur $(1.3 \mathrm{wt}-\%)$ and carbon $(0.7 \mathrm{wt}-\%)$ in the layers plated from chromium(III)-based electrolyte probably originating from the organic additive saccharine. In contrast, the deposition from chromic acid electrolyte yields an almost pure layer of chromium (99.4 wt-\%) with no sulfur and even smaller amount of carbon $(0.4 \mathrm{wt}-\%)$. Oxygen can be found in both cases due to the formation of oxides in contact with air. Although the differences in composition are comparably small, they might have slight influence on the visual appearance of the surface, but superimposed by the influence of the surface morphology.

The increasing grain size has a strong influence on the roughness of chromium plated from chromium(III) electrolyte. As can be seen from AFM images of the three samples discussed above (Figures 6 and 7), the roughness increases with increasing deposition time. Furthermore, the surface structure becomes more and more heterogeneous due to the globular-like growth of chromium. Very large and small grains are present side by side on the sample surface. The roughness parameters $\mathrm{Ra}$ and $\mathrm{Rq}$ are given in Table $\mathrm{V}$. By this means, the color shift from

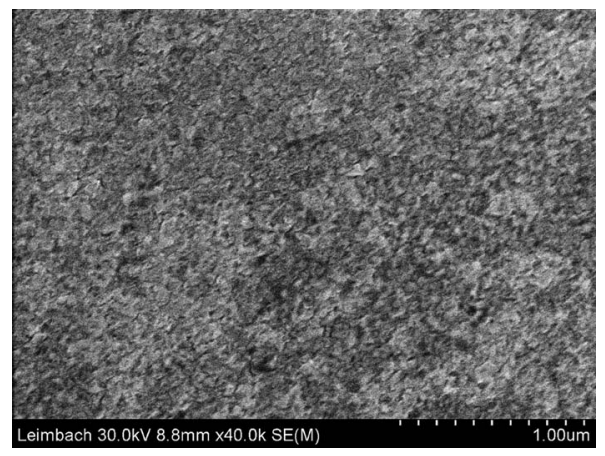

Figure 5. SEM image of the chromium layer electroplated from the chromic acid based electrolyte.

\begin{tabular}{|c|c|c|}
\hline \multirow[b]{2}{*}{ Element } & \multicolumn{2}{|c|}{ Concentration [wt-\%] } \\
\hline & Chromium(III) electrolyte & Chromic acid electrolyte \\
\hline $\mathrm{Cr}$ & 96.2 & 99.4 \\
\hline S & 1.3 & - \\
\hline $\mathrm{C}$ & 0.7 & 0.4 \\
\hline $\mathrm{O}$ & 1.8 & 0.2 \\
\hline
\end{tabular}

blueish to yellowish can be explained by the theory of light scattering at rough surfaces. ${ }^{22}$

Modeling of spectral reflectance curves.-For a mirror-bright surface, it can be assumed that the fraction of the diffusely reflected light is negligible compared to the specular reflected light, so that diffuse reflection can be omitted. The attenuated intensity of specular reflected light is defined by Eq. 8 .

$$
I(\lambda)=I_{0}(\lambda) \cdot \exp (-g(\lambda))
$$

$I(\lambda)$ and $I_{0}(\lambda)$ are the intensities of the reflected and the incident light, respectively. The roughness parameter $g(\lambda)$ can be specified in different ways. Eq. 9 is based on Kirchhoff's theory of diffraction. ${ }^{23}$

$$
g(\lambda)=\frac{4 \pi \cdot \cos \delta}{\lambda} \cdot R q
$$

Secondly, Eq. 10 is derived from Beckmann's formula. ${ }^{24}$

$$
g(\lambda)=2 \cdot\left(\frac{2 \pi \cdot \cos \delta}{\lambda} \cdot R q\right)^{2}
$$

In Eqs. 9 and $10, \delta$ is the incident angle, $\lambda$ the wavelength and $\mathrm{Rq}$ is the root mean square surface roughness (standard deviation of the surface profile height). It can be seen, in any case, that the attenuation increases with increasing roughness and is higher for small wavelengths. Therefore, if the roughness is increased during layer growth, the decrease of reflectance is higher in the blue-green range of the spectrum than in the yellow-red range, which is in good agreement with the results discussed above. Similar conclusions on roughness-dependent reflectance were drawn for electroplated nickel, ${ }^{25}$ copper ${ }^{26}$ and silver, ${ }^{27}$ but with measuring the intensity of reflected light under directional illumination. In all cases, a loss of brightness was observed when the average roughness exceeded a threshold value.

The material-dependent influence on the reflectance is given by the Fresnel Equations. Since the color measurements are performed under an incident angle close to normal, the simplified Fresnel equation for normal incidence (Eq. 11) can be applied. ${ }^{28}$

$$
\begin{gathered}
R(\lambda)=\left|\frac{1-\boldsymbol{n}(\lambda)}{1+\boldsymbol{n}(\lambda)}\right|^{2}=\frac{(n(\lambda)-1)^{2}+k(\lambda)^{2}}{(n(\lambda)+1)^{2}+k(\lambda)^{2}} \\
\boldsymbol{n}(\lambda)=n(\lambda)+\boldsymbol{i} \cdot k(\lambda)
\end{gathered}
$$

$\mathbf{n}(\lambda)$ is the complex index of refraction, $n(\lambda)$ the refractive index (real part of $\mathbf{n}(\lambda)$ ) and $\mathrm{k}(\lambda)$ the extinction coefficient (imaginary part of

Table V. Roughness values of the chromium layers electroplated from chromium(III)-based electrolyte.

\begin{tabular}{lll} 
Chromium layer thickness/nm & $\mathrm{Ra} / \mathrm{nm}$ & $\mathrm{Rq} / \mathrm{nm}$ \\
\hline 20 & 2.8 & 3.5 \\
140 & 8.1 & 9.7 \\
380 & 15.7 & 19.3
\end{tabular}



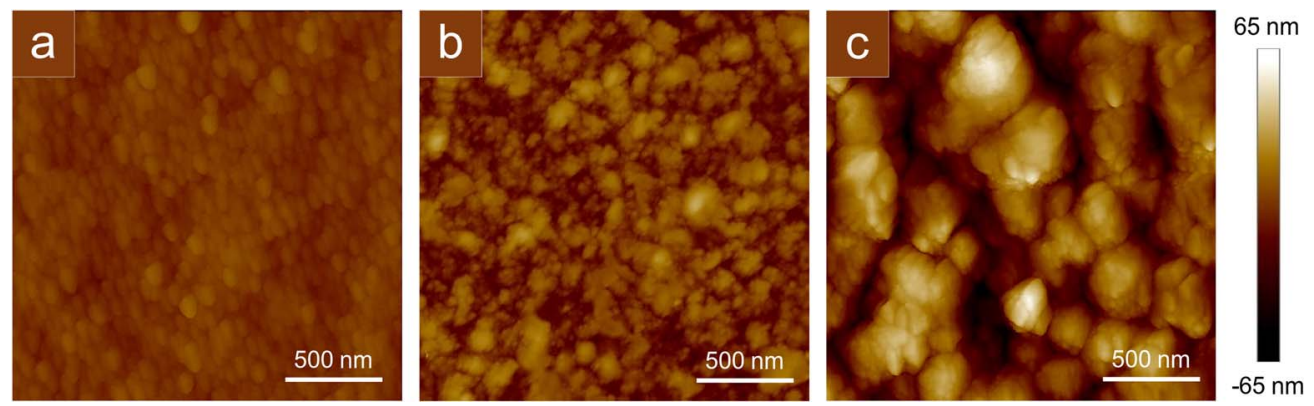

Figure 6. AFM images of the chromium layers electroplated from the chromium(III)-based electrolyte (Table II) with a layer thickness of a) $20 \mathrm{~nm}$, b) $140 \mathrm{~nm}$ and c) $380 \mathrm{~nm}$.
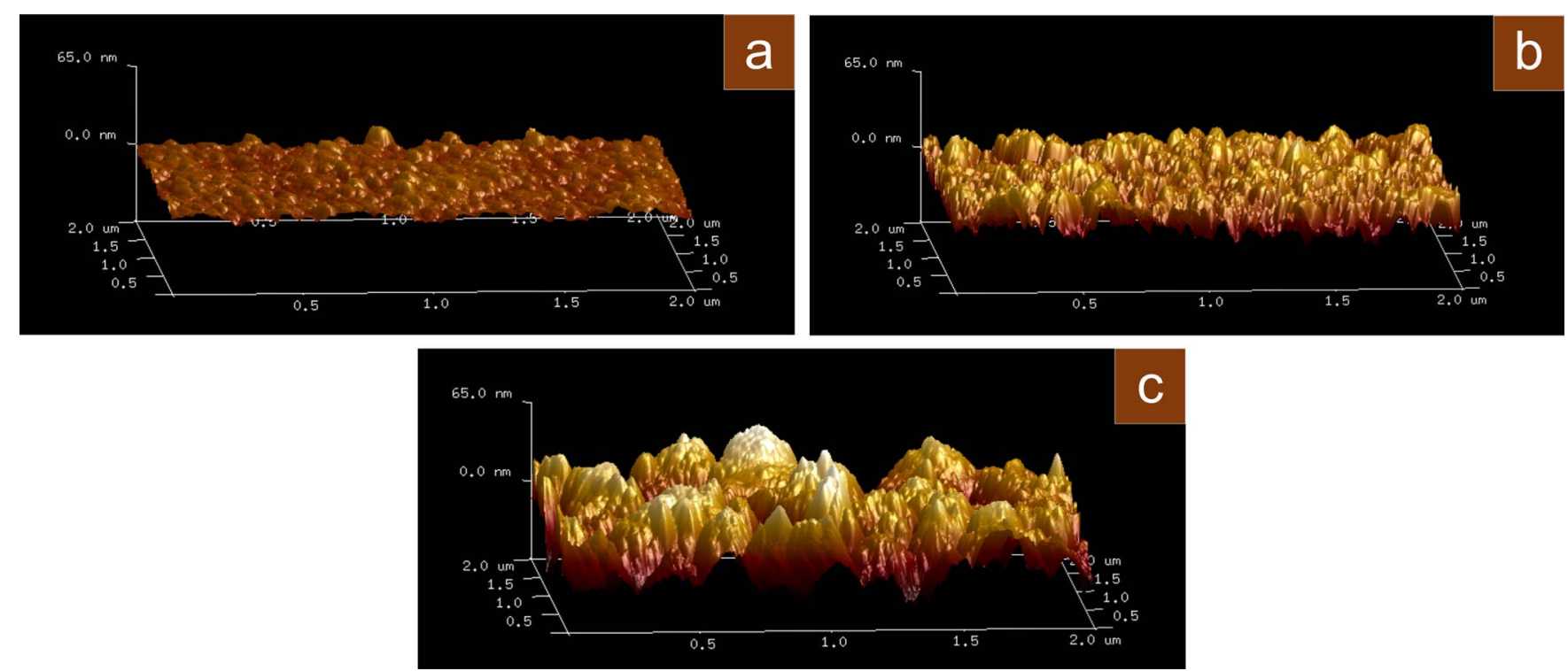

Figure 7. AFM surface profiles of the chromium layers electroplated from the chromium(III)-based electrolyte with a layer thickness of a) $20 \mathrm{~nm}$, b) $140 \mathrm{~nm}$ and c) $380 \mathrm{~nm}$.

$\mathbf{n}(\lambda))$ The spectral reflectance $R(\lambda)$ is defined as the ratio of intensities of the reflected and the incident light (Eq. 13).

$$
R(\lambda)=\frac{I(\lambda)}{I_{0}(\lambda)}
$$

Eq. 9

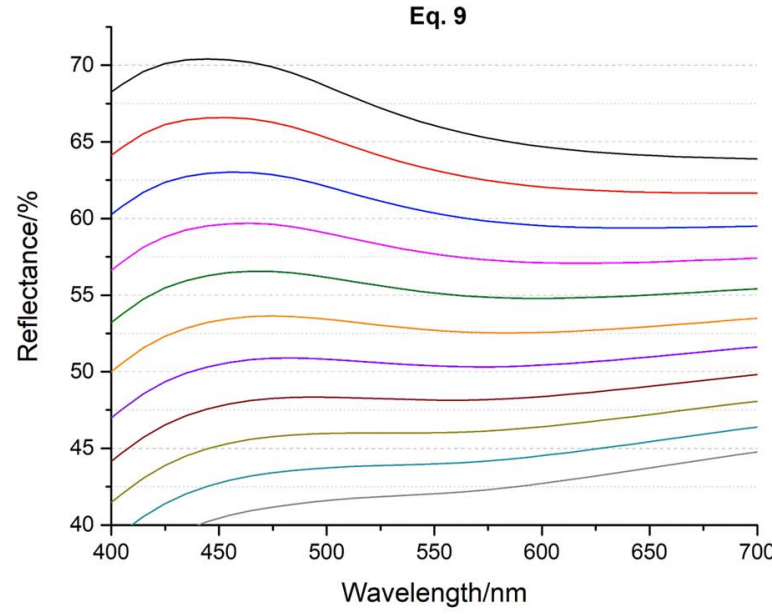

The combination of Eqs. 8 and 11 gives a roughness-dependent model of the reflectance on a metal surface (Eq. 14).

$$
R(\lambda)=\frac{(n(\lambda)-1)^{2}+k(\lambda)^{2}}{(n(\lambda)+1)^{2}+k(\lambda)^{2}} \cdot \exp (-g(\lambda))
$$

Eq. 10
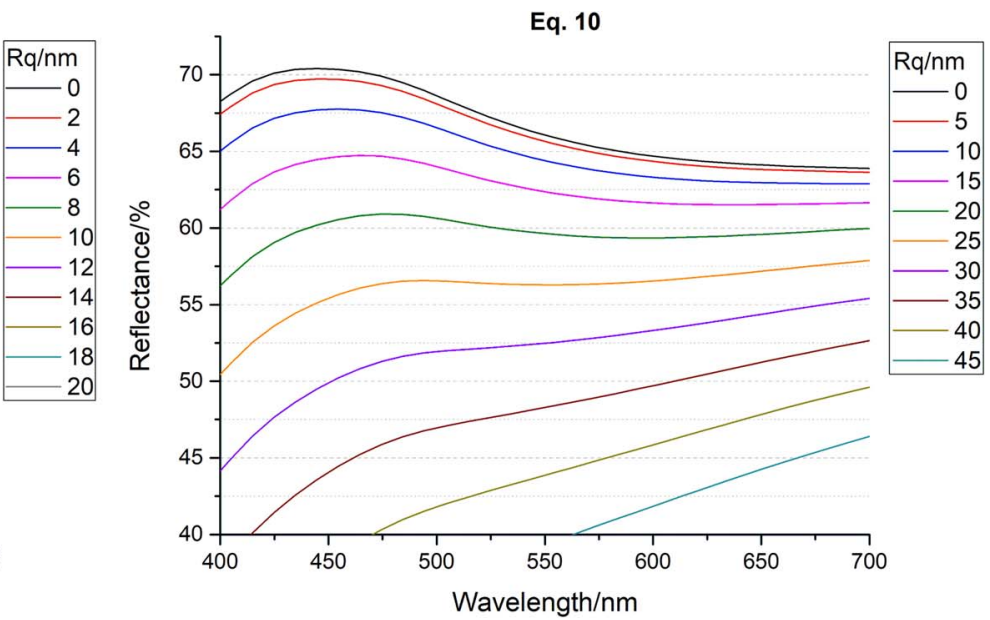

Figure 8. Calculated reflectance curves of chromium in dependence of Rq using the model based on Eq. 9 (left) and Eq. 10 (right), respectively. 


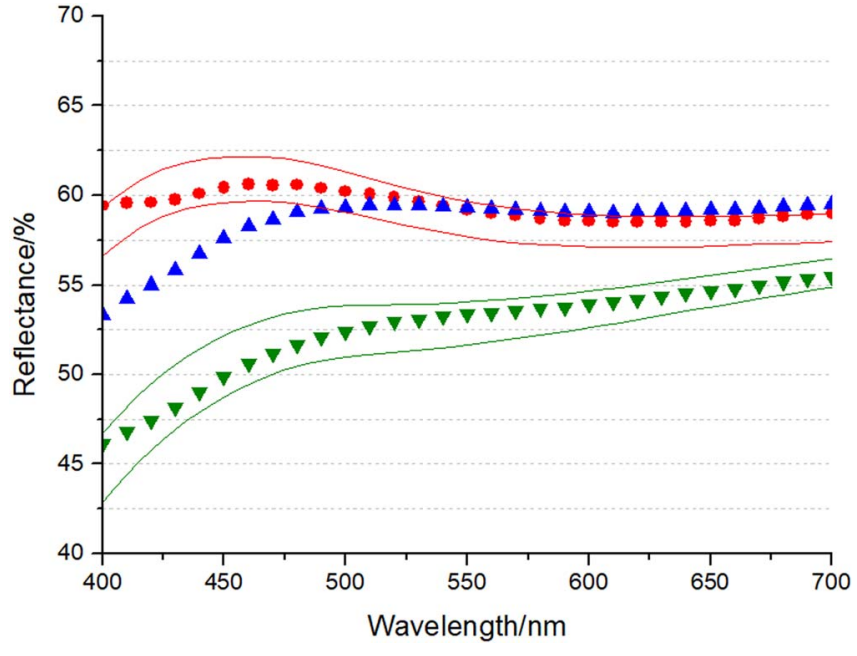

Figure 9. Comparison between measured and calculated reflectance curves of chromium. The markers indicate the measured curves of the layers electroplated from chromium(III) with a thickness of $20 \mathrm{~nm}$ (red), $140 \mathrm{~nm}$ (blue) and $380 \mathrm{~nm}$ (green). The red solid curves are calculated using the model based on Eq. 9 $(\mathrm{Rq}=4.5$ and $6 \mathrm{~nm})$ and the green solid curves using the model based on Eq. $10(\mathrm{Rq}=28$ and $31 \mathrm{~nm})$, respectively.

The data for $\mathrm{n}(\lambda)$ and $\mathrm{k}(\lambda)$ for chromium are taken from literature, ${ }^{29}$ assuming a polycrystalline layer with randomly oriented crystallites. Spectral reflectance curves of chromium were calculated for several values of $\mathrm{Rq}$ (Figure 8 ) at an incident angle of $8^{\circ}$, the same as applied in the measurement of the spectra in Figure 1. Separate graphs were calculated for both equations of $\mathrm{g}(\lambda)$. The spectrum at $\mathrm{Rq}=0$ has a maximum reflectance at a wavelength of $445 \mathrm{~nm}$. As expected, if the roughness is increased, the overall reflectance is decreasing, but more strongly in the blue-green range than in the yellow-red range. For Eq. 9, the effect of roughness is more pronounced than for Eq. 10. At a Rq $>10 \mathrm{~nm}$ for Eq. 9 and $\mathrm{Rq}>21 \mathrm{~nm}$ for Eq. 10, the reflectance at $700 \mathrm{~nm}$ exceeds the reflectance at $445 \mathrm{~nm}$, so that a color change from blueish to yellowish can be predicted. Thus, the relationship between roughness and color is confirmed qualitatively.

In comparison with the measured spectra of the sample plated from chromium(III) solution (Figure 9), the spectrum of the $20 \mathrm{~nm}$ thick layer matches quite well with the model based on Eq. 9 with $\mathrm{Rq}$ in the range of 4.5 to $6 \mathrm{~nm}$. In fact, the measured $\mathrm{Rq}$ amounts $3.5 \mathrm{~nm}$. On the other hand, the $380 \mathrm{~nm}$ thick sample fits best to the calculation on basis of Eq. 10 for Rq between 28 and $31 \mathrm{~nm}$. Again, the modelled roughness value is about $30 \%$ higher than the measured one $(19.3 \mathrm{~nm})$. The overestimation of the roughness might be due to a non-Gaussian distribution of profile height in the measured surface profile, while the model assumes a Gaussian distribution.

Respecting this overestimation, it can be assumed that the model using Eq. 9 is more suitable for low chromium thicknesses, i. e. low values of Rq, and the model based on Eq. 10 for high thicknesses. This is caused not only by the increase of roughness, but also by the change of grain size distribution that comes along with the heterogeneous grain growth. The reflectance curve of the $140 \mathrm{~nm}$ sample matches to none of the models. Probably it can be attributed to a transition zone of both models. Misfits between measurement and model, especially in the blue range between 400 and $500 \mathrm{~nm}$, are due to uncertainties in the values of $n(\lambda)$ and $k(\lambda)$. The data given in literature differ ${ }^{30-32}$ as they depend strongly on surface preparation, microstructure and crystal orientation.

\section{Conclusions}

Chromium layers electrodeposited from a chromium(III) sulfate based electrolyte were characterized by colorimetry, SEM and AFM and compared to a sample plated from a chromic acid electrolyte.
The visual appearance of the chromium strongly depends on the morphology of the surface. With increasing layer thickness, a color shift from blueish to yellowish was observed that can be correlated with an increase in grain size and roughness. In this regard, chromium from trivalent solution exhibits a globular-like type of layer growth that is different from the columnar growth mode in chromic acid electrolytes, so that the appearance differs at high layer thickness.

The relationship between color and roughness is supported by calculations based on the theory of light scattering on rough surfaces. Different equations have been used to model the reflection behavior in dependence of chromium layer thickness and roughness. The provided model is applicable for electrodeposited chromium with a small amount of impurities, like typical bright chromium layers. If the deposit has a high content of foreign elements, e. g. carbon or sulfur, other effects can interfere and the correlations are no longer valid.

\section{Acknowledgments}

The research was done within the framework of a cooperation between Technische Universität Ilmenau and Hansgrohe SE. EFRE (European Regional Development Fund) and DFG (German Research Foundation) are kindly acknowledged for the financial support provided for the purchase of the AFM device (DFG-Gz: INST 273/56-1 FUGG)

\section{ORCID}

Martin Leimbach (D) https://orcid.org/0000-0002-9548-7653

Andreas Bund (D) https://orcid.org/0000-0001-9837-2408

\section{References}

1. J. H. Lindsay, Plat. Surf. Finish., 84(8), 50 (1997).

2. European Chemicals Agency, Authorisation List, EC No. 215-607-8, 231-801-5, 231 889-5, 231-906-6, 232-140-5, 232-143-1, 234-190-3, 236-881-5.

3. V.S. Protsenko and F. I. Danilov, Clean Technol. Envir., 16(6), 1201 (2014).

4. Z. X. Zeng, A. M. Liang, and J. Y. Zhang, Recent Pat. Mater. Sci., 2(1), 50 (2009).

5. D. Del Pianta, J. Frayret, C. Gleyzes, C. Cugnet, J. C. Dupin, and I. Le Hecho, Electrochim. Acta, 284, 234 (2018).

6. H. H. Sheu, C. H. Lin, S. Y. Jian, H. B. Lee, B. R. Yang, and M. D. Ger, Int. J. Electrochem. Sc., 11(8), 7099 (2016).

7. M. E. Inman, E. J. Taylor, T. D. Hall, S. Snyder, and S. Lucatero, Collaborative Development of a Functional Trivalent Chromium Electroplating Process, ECS Meeting, Phoenix (2015).

8. D. L. Snyder, Met. Finish., 2(110), 14 (2012).

9. S. L. Handy, C. F. Oduoza, and T. Pearson, Trans. IMF, 84(6), 300 (2006).

10. D. L. Snyder, Plat. Surf. Finish., 90(11), 34 (2003).

11. A. M. Liang and J. Y. Zhang, Surf. Coat. Tech., 206(17), 3614 (2012).

12. K.-D. Schulz, P. Wachter, and P. Hartmann, Electroplating Bath and Method for Producing Dark Chromium Layers, US Pat. 10006135 B2 (2018).

13. M. Leimbach, C. Tschaar, U. Schmidt, and A. Bund, Electrochim. Acta, 270, 104 (2018).

14. CIE Technical Report No. 15, Colorimetry, 3rd ed. (2004)

15. T. Smith and J. Guild, Trans. Opt. Soc., 33(3), 73 (1931).

16. ASTM E 308 - 01, Standard Practice for Computing the Colors of Objects by Using the CIE System.

17. D. L. MacAdam, J. Opt. Soc. Am., 32(5), 247 (1942).

18. H. Pauli, J. Opt. Soc. Am., 66(8), 866 (1976).

19. N. N. Martyak and R. Weil, Trans. IMF, 71(4), 133 (1993).

20. C. Bergenstof Nielsen, P. Leisner, and A. Horsewell, J. Appl. Electrochem., 28(2), 141 (1998).

21. D. Wardecki, R. Przenioslo, A. N. Fitch, M. Bukowski, and R. Hempelmann, J. Nanopart. Res., 13(3), 1151 (2011).

22. P. Beckmann and A. Spizzichino, The Scattering of Electromagnetic Waves From Rough Surfaces, Artech House, Norwood, MA (1987).

23. S. Iwasaki and T. Mukai, Simulation for Light Scattering by Rough Surface based on Kirchhoff's Diffraction Theory, in Exploration of Small Bodies in the Solar System: Related Laboratory and Modelling Studies, Vol. 23, pp. 1213, Pergamon Press, Oxford (1999).

24. V. Goossens, N. Gotzen, S. Van Gils, E. Stijns, G. Van Assche, R. Finsy, and H. Terryn, Surf. Coat. Tech., 204(5), 551 (2009).

25. R. Weil and R. Paquin, J. Electrochem. Soc., 107(2), 87 (1960). 
26. N. D. Nikolić, Z. Rakočević, and K. I. Popov, J. Electroanal. Chem., 514(1-2), 56 (2001).

27. B. Zheng, L. P. Wong, L. Y. L. Wu, and Z. Chen, Adv. Mater. Sci. Eng., 2017, Article ID 7686983 (2017)

28. M. Bass (ed.), Handbook of Optics, Vol. 1, 3rd ed., p. 12.6ff, McGraw-Hill, New York (2009).
29. W. M. Haynes, D. R. Lide, and T. J. Bruno, (eds.), CRC Handbook of Chemistry and Physics, 97th ed., p. 12-127, CRC Press, Boca Raton, FL (2017).

30. L. Bos and D. W. Lynch, Phys. Rev. B, 2(11), 4567 (1970).

31. P. B. Johnson and R. W. Christy, Phys. Rev. B, 9(12), 5056 (1974).

32. A. D. Rakić, A. B. Djurišic, J. M. Elazar, and M. L. Majewski, Appl. Optics, 37(22), 5271 (1998). 